\title{
Female Sexual Dysfunction in Type 2 Diabetes: A Case Control Study
}

\author{
Farzaneh Sharifiaghdas Mohaddeseh Azadvari Nasser Shakhssalim \\ Kobra Roohi-Gilani Mohsen Rezaei-Hemami \\ Urology and Nephrology Research Center, Shahid Labbafinejad Medical Center, Shahid Beheshti University of \\ Medical Sciences, Tehran, Iran
}

\section{Key Words}

Female sexual dysfunction • Diabetes mellitus

\begin{abstract}
Objective: This study was designed to assess sexual dysfunction in women suffering from type 2 diabetes mellitus.

Subjects and Methods: Forty-five type 2 diabetic, nonmenopausal married women, aged 20-55 years, who were referred to Shahid Labbafinejad Clinics from March 2008 to June 2009 were included in this study. They were compared to 91 non-diabetic volunteers. Sexual function was evaluated by the sexual function questionnaire. Genitourinary examination was performed in all subjects. Blood sample tests were requested for fasting blood sugar, hemoglobin $A_{1 c}$, 2-hour postprandial glucose and lipid profile measurements. Ophthalmologic and neurologic examinations (checking deep tendon reflexes) were done for cases. Results: The mean age of cases and controls was 42.17 5.91 and 34.96 \pm 8.30 years, respectively $(p<0.001)$. The prevalence of a high probability of female sexual dysfunction in 6 domains including desire, arousal sensation, arousal lubrication, orgasm, pain and enjoyment was 71.1, 84.4, 55.6, 71.1, 8.9 and $66.7 \%$ in the diabetes mellitus women and 56.6, 67.0, 59.3, $57.1,25.3$ and $53.8 \%$ in the non-diabetic volunteers, respec-
\end{abstract}

tively. Differences were statistically significant in the 3 domains of desire, arousal sensation and pain $(p<0.05)$. Deep tendon reflexes were normal in all and $12.5 \%$ showed diabetic retinopathy. Conclusions: Sexual dysfunction in cases as well as in controls was high; however, further studies with a higher number of patients are needed to confirm the results.

Copyright $\odot 2012$ S. Karger AG, Basel

\section{Introduction}

Diabetes mellitus is a common disease that may impair sexual activity in men and women. According to the American Diabetes Association, 20.8 million (7\%) of Americans have been diagnosed with diabetes mellitus [1]. In men, diabetes mellitus has long been recognized as a major risk factor for impaired sexual function as 20 to $>70 \%$ of diabetes mellitus men suffer from sexual dysfunction that include primary erectile dysfunction, pre-ejaculation, orgasm and desire [2-4]. Female sexual dysfunction is a highly prevalent health problem affecting $25-63 \%$ of women [5-7]; the prevalence of female sexual dysfunction and the associated risk factors are less clear than in men [8]. Estimates of the prevalence of 
Table 1. Characteristics of cases and controls

\begin{tabular}{lcc}
\hline Variable & Cases $(\mathrm{n}=45)$ & Controls $(\mathrm{n}=90)$ \\
\hline Smoking & & \\
$\quad$ Smoker & $0(0.00)$ & $6(6.6)$ \\
$\quad$ Non-smoker & $45(100.00)$ & $85(93.4)$ \\
Level of academic education & & \\
$\quad$ University & $7(15.56)$ & $15(16.48)$ \\
$\quad$ High school or lower level & $38(84.44)$ & $76(83.52)$ \\
Job & & \\
Housewife & $43(95.56)$ & $77(84.62)$ \\
Employed & $2(4.44)$ & $14(15.38)$ \\
Menstruation & & \\
Regular & $35(77.78)$ & $66(72.53)$ \\
Irregular & $10(22.22)$ & $25(27.47)$ \\
Contraception method used & & \\
$\quad$ None & $4(8.89)$ & $16(17.58)$ \\
$\quad$ Natural & $9(20.00)$ & $18(19.78)$ \\
Barrier & $9(20.00)$ & $21(23.08)$ \\
Tubal ligation & $7(15.56)$ & $10(10.99)$ \\
Oral contraceptive & $5(11.11)$ & $6(6.59)$ \\
Vasectomy & $4(8.89)$ & $6(6.59)$ \\
Intrauterine device & $7(15.56)$ & $14(15.38)$ \\
\hline
\end{tabular}

Figures in parentheses are percentages.

female sexual dysfunction vary greatly depending on the definition, the assessment tool used and population demographics (education, marital status, age and race) [9].

In this study, we evaluated female sexual dysfunction in type 2 diabetic mellitus non-menopausal women in comparison with non-diabetic volunteers with the same age range.

\section{Subjects and Methods}

Our study was approved by the Ethics Committee of Shahid Beheshti University of Medical Sciences.

Forty-five type 2 diabetic mellitus, non-menopausal married women, aged 20-55 years, were included in this study from March 2008 to June 2009 at the Shahid Labbafinejad Medical Center. The control group included 91 non-diabetic, married volunteers with the same age range. An internal medicine specialist and endocrinologist (R.G.K.) confirmed the type of diabetes mellitus. Exclusion criteria were: married women who lived apart from their spouses; history of major diseases such as neoplasm, heart failure or end organ damage such as chronic renal failure; history of sexual abuse, major depression, or history of regular use of antidepressants or anxiolytics, as well as signs of severe organ prolapse such as uterine prolapse, cystocele stage $\geq 3$ or signs of perineal iatrogenic severe scars (due to previous surgeries) which prohib-

Sexual Dysfunction in Women with

Diabetes Mellitus and Non-Diabetics ited effective entrance. At the first visit, patients and controls got a code number. A general physician filled in the demographic questionnaire for all participants. Both groups filled in the sexual function questionnaire (SFQ) by themselves with or without the aid of an assistant (Appendix).

The SFQ contained 31 questions evaluating sexual function in 6 domains: desire, arousal sensation, arousal lubrication, orgasm, pain, and enjoyment. All subjects obtained a score for each domain. According to their scores, women were categorized into three groups: high probability for sexual dysfunction, borderline probability for normal sexual function, and high probability for normal sexual function (Appendix).

Venous blood samples were withdrawn for fasting blood sugar, glycosylated hemoglobin $A_{1 c}$, 2-hour postprandial glucose test and lipid profile (cholesterol, triglyceride, low-density lipoprotein, high-density lipoprotein) measurements in both groups. Genitourinary examination was performed in mid-cycle at lithotomy position by an experienced female urologist (F.S.), and the patient was evaluated for evidence of pelvic organ prolapse based on pelvic organ prolapse quantification [10] or any severe perineal iatrogenic scars. To evaluate the effect of diabetes on sensory motor response, a monofilament test and deep tendon reflexes were carried out in all diabetic cases. All diabetic patients were referred to an experienced ophthalmologist to test for signs of retinopathy.

Data were evaluated using SPSS 16 software. Data are reported as the mean and standard deviation for continuous variables and frequency and relative frequency for categorical variables. Groups were compared using the $\mathrm{t}$ and $\chi^{2}$ test; for multivariate analysis, ANCOVA was used. The statistically significant level was set at $\mathrm{p}<0.05$.

\section{Results}

The age range of both the case and the control group (20-55 years) was $42.1 \pm 5.9$ and $34.9 \pm 8.3$ years, respectively, and the difference was statistically significant $(\mathrm{p}<0.001)$.

The characteristics of the case and control groups are shown in table 1 . The mean body mass index of diabetics and controls was $29.2 \pm 5.9$ and $26.4 \pm 4.2$, respectively $(\mathrm{p}<0.001)$. The mean duration of diabetes mellitus in the case group was $6.35 \pm 5.41$ years.

Only $2(4.4 \%)$ patients had reduced results in the monofilament test. Deep tendon reflex tests were normal in all cases. The characteristics of diabetes mellitus patients are shown in table 2.

Thirty-four (75.6\%) and 55 (61.1\%) subjects of the control group had a history of genitourinary and colorectal surgery. Twenty-four (53.3\%) cases showed results of ophthalmologic examination; 3 (12.5\%) had diabetic retinopathy.

The mean serum level of fasting blood sugar for cases and controls was 162.83 versus $89.11 \mathrm{mg} / \mathrm{dl}$, and for tri- 
Table 2. Characteristics of diabetes mellitus patients

\begin{tabular}{lc}
\hline Variable & Patients \\
\hline Type of diabetes mellitus control & \\
Medical nutrition treatment & $4(8.9)$ \\
Oral tablets & $33(73.3)$ \\
Insulin & $8(17.8)$ \\
Hypertension disease & $11(24.4)$ \\
Yes & $34(75.6)$ \\
No & \\
Impaired monofilament test & $1(2.2)$ \\
Yes & $44(97.8)$ \\
No & \\
Cardiovascular diseases & $40(88.9)$ \\
Normal & $1(2.2)$ \\
History of myocardial infarction & $2(4.4)$ \\
Valvular disease & $1(2.2)$ \\
Cardiac angina & $1(2.2)$ \\
$\quad$ Mitral valve prolapse & \\
\hline
\end{tabular}

Figures in parentheses are percentages.

glyceride, 176.44 and $126.69 \mathrm{mg} / \mathrm{dl}$ (table 3), respectively. There was a statistically significant difference between cases and controls.

Of the 45 cases and 91 controls, 32 (71\%) and 51 (56\%) suffered from dysfunction in sexual desire, respectively ( $\mathrm{p}=0.009$; table 4 ; Appendix). Thirty-eight $(84 \%)$ cases and $61(67 \%)$ controls suffered from arousal sensation problems; the difference was statistically significant $(\mathrm{p}=$ 0.027). Also, 4 (8.9\%) cases and $23(25.3 \%)$ controls had pain disorders. There was no significant relationship between sexual function, body mass index, job, smoking, and glycemic control.

\section{Discussion}

In our study, the domains of desire and arousal sensation were more adversely affected in the cases than in the control group ( $p<0.05)$, as previously reported $[11,12]$. The World Health Organization recognized the importance of human sexuality as part of an individual's health and well being in 1974 [13]. Several factors contribute to sexual activity in women such as sexual education, economic status and relationship with partner, family issues, depression and others. The high rate of desire and arousal sensation dysfunction in our study may be related to the higher mean age, higher body mass index, vascular disorders and the negative effect of a chronic disease on
Table 3. Comparison of blood sample parameters between cases and controls

\begin{tabular}{lccl}
\hline $\begin{array}{l}\text { Blood sample } \\
\text { parameters }\end{array}$ & Cases & Controls & $\begin{array}{l}\mathrm{p} \\
\text { value }\end{array}$ \\
\hline $\begin{array}{l}\text { Fasting blood sugar } \\
\text { 2-hour postprandial } \\
\text { glucose }\end{array}$ & $162.83 \pm 58.48$ & $89.11 \pm 9.80$ & $<0.001$ \\
Hemoglobin $\mathrm{A}_{1 \mathrm{c}} \%$ & $209.57 \pm 88.25$ & $100.34 \pm 19.66$ & $<0.001$ \\
Blood urea nitrogen & $7.88 \pm 1.85$ & $5.46 \pm 1.06$ & $<0.001$ \\
Creatinine & $13.08 \pm 3.01$ & $12.46 \pm 3.39$ & 0.37 \\
Cholesterol & $0.090 \pm 0.19$ & $0.91 \pm 0.16$ & 0.81 \\
Triglyceride & $181.50 \pm 45.57$ & $174.30 \pm 42.34$ & 0.42 \\
Low-density lipoprotein & $176.44 \pm 79.93$ & $126.69 \pm 80.73$ & 0.003 \\
High-density lipoprotein & $98.89 \pm 37.82$ & $91.64 \pm 24.50$ & 0.31 \\
& $45.09 \pm 10.12$ & $42.97 \pm 9.76$ & 0.29 \\
\hline
\end{tabular}

Data are means $\pm \mathrm{SD}$, given in $\mathrm{mg} / \mathrm{dl}$.

Table 4. Comparison of the 6 domains of female sexual dysfunction in cases and controls based on the SFQ

\begin{tabular}{|c|c|c|c|c|}
\hline Domains & $\begin{array}{l}\text { High probability } \\
\text { of sexual } \\
\text { dysfunction }\end{array}$ & $\begin{array}{l}\text { Borderline } \\
\text { probability } \\
\text { of normal } \\
\text { sexual function }\end{array}$ & $\begin{array}{l}\text { Normal } \\
\text { sexual } \\
\text { function }\end{array}$ & $\mathrm{p}$ value \\
\hline \multicolumn{5}{|l|}{ Desire } \\
\hline $\begin{array}{l}\text { Cases } \\
\text { Controls }\end{array}$ & $\begin{array}{l}32(71.1) \\
47(56.6)\end{array}$ & $\begin{array}{l}13(28.9) \\
35(38.5)\end{array}$ & $\begin{array}{l}0(0.0) \\
9(9.9)\end{array}$ & 0.009 \\
\hline \multicolumn{5}{|c|}{ Arousal sensation } \\
\hline $\begin{array}{l}\text { Cases } \\
\text { Controls }\end{array}$ & $\begin{array}{l}38(84.4) \\
61(67.00)\end{array}$ & $\begin{array}{r}5(11.1) \\
17(18.7)\end{array}$ & $\begin{array}{c}2(4.4) \\
13(14.3)\end{array}$ & 0.027 \\
\hline \multicolumn{5}{|c|}{ Arousal lubrication } \\
\hline $\begin{array}{l}\text { Cases } \\
\text { Controls }\end{array}$ & $\begin{array}{l}25(55.6) \\
54(59.3)\end{array}$ & $\begin{array}{l}13(28.9) \\
18(19.8)\end{array}$ & $\begin{array}{r}7(15.6) \\
19(20.9)\end{array}$ & 0.915 \\
\hline \multicolumn{5}{|l|}{ Orgasm } \\
\hline $\begin{array}{l}\text { Cases } \\
\text { Controls }\end{array}$ & $\begin{array}{l}32(71.1) \\
52(57.1)\end{array}$ & $\begin{array}{r}9(20.0) \\
30(33.0)\end{array}$ & $\begin{array}{l}4(8.9) \\
9(9.9)\end{array}$ & 0.218 \\
\hline \multicolumn{5}{|l|}{ Pain } \\
\hline $\begin{array}{l}\text { Cases } \\
\text { Controls }\end{array}$ & $\begin{array}{c}4(8.9) \\
23(25.3)\end{array}$ & $\begin{array}{l}11(24.4) \\
24(26.4)\end{array}$ & $\begin{array}{l}30(66.7) \\
44(48.4)\end{array}$ & 0.016 \\
\hline \multicolumn{5}{|l|}{ Enjoyment } \\
\hline $\begin{array}{l}\text { Cases } \\
\text { Controls }\end{array}$ & $\begin{array}{l}30(66.7) \\
49(53.8)\end{array}$ & $\begin{array}{l}14(31.1) \\
36(39.6)\end{array}$ & $\begin{array}{l}1(2.2) \\
6(6.6)\end{array}$ & 0.113 \\
\hline
\end{tabular}

Figures in parentheses are percentages.

mood. Pain was more frequent in the control than in the case group which could be due to a better sensation, compared to diabetics.

Loss of vaginal lubrication, reduced sensation and sexual pleasure in women with type 2 diabetes as observed in this study is similar to that reported by Meeking et al. 
[14] in type 1 and type 2 diabetic women. Similar observations have been reported by Fatemi and Taghavi [15] in type 2 diabetic women. In the investigation of SchreinerEngel et al. [16] of cognitive, psychological, interpersonal, and sexual dimensions with diabetes, diabetic women showed a relatively low impairment in sexual responses, but sexual desire was significantly lower. The observations could be attributed to the changes in life style, psychological state, neurologic and vascular deficits during a chronic disease such as diabetes.

Pain disorders of $8.9 \%$ in our study was lower than the $26 \%$ reported by Safarinejad [17] in a population-based study of 2,626 women, aged 20-29 years. Probably, the wider age range of 20-55 years in our study could explain the difference between the two studies.

In conclusion, prevalence of sexual dysfunction in diabetic mellitus women and controls was high; however, as the number of cases was limited, further studies with a higher number of patients are needed to confirm the results.

\section{Acknowledgement}

The authors wish to acknowledge Prof. M. Baradaran for his technical assistance in the ophthalmologic examination of patients.

\section{Appendix: The Female SFQ}

The SFQ contains 31 items and each item has 5 or 7 possible response options

Items 1-5, 25, 26 and 31 were scored 1-5 (in ascending order), e.g.,

1. Over the last 4 weeks, how often have you had pleasurable thoughts and feelings about sexual activity?

1 Not at all

2 Rarely

3 Sometimes

4 Often

5 Very often

Items 6-12, 14, 18, 19 and 21-24 were scored 1-5 (in ascending order) with the 'not applicable' category (e.g., 'I did not take part in sexual activity', 'I did not have any orgasms') set to 'missing', e.g.,

6. Over the last 4 weeks, in general, how enjoyable has it been to be sensually touched and caressed by your partner?

I have not been touched or caressed (missing)

1 Not enjoyable

2 Slightly enjoyable

3 Moderately enjoyable

4 Very enjoyable

5 Extremely enjoyable
Items 13 and 17 were scored 0-6 (in ascending order), e.g.,

13. Over the last 4 weeks, how often did you take part in sexual activity with penetration (e.g., vaginal penetration and intercourse)?

$0 \quad$ I did not take part in sexual activity

1 Once/twice

2 3-4 times

3 5-8 times

4 9-12 times

5 13-16 times

$6>16$ times

Items 15, 16, 27, 28 and 29 were scored 1-5 (in descending order; for items 15,16 and 27 , the 'I did not take part in sexual activity' category is set to 'missing'), e.g.,

28. Thinking about the last 4 weeks, how much did you worry that your partner may look for another sexual relationship because of problems with your sexual life?

5 Not at all

4 Slightly

3 Moderately

2 Very

1 Extremely

Item 20 is scored from 5-1 with the 'I did not take part in sexual activity' scored as 'missing' and the 'I did not take part in sexual activity because of being worried or anxious about pain' scored as 0 , i.e.

20. Over the last 4 weeks, how often have you been worried or anxious about pain during sexual activity?

I did not take part in sexual activity (missing)

0 I did not take part in sexual activity because of being worried or anxious about pain

5 Not at all

4 Sometimes

3 Often

2 Very often

1 Every time

Note: item 30 was not included in the overall scoring but may be tabulated if desired.

Total score: A total score may be derived from summing the individual item scores, except item 32 . The total score range is $30-167$. A higher score indicates better sexual function.

Domain scores (seven domains have been identified through factor analysis)

\begin{tabular}{lllll}
\hline Domain & Items, n & Item No. & $\begin{array}{l}\text { Score } \\
\text { range }\end{array}$ & $\begin{array}{l}\text { Scores suggesting } \\
\text { normal function }\end{array}$ \\
\hline Desire & 6 & $1-4,13,26$ & $5-31$ & $>23$ \\
Arousal (S) & 4 & $7-10$ & $4-20$ & $>14$ \\
Arousal (L) & 2 & 11,12 & $2-10$ & $>8$ \\
Orgasm & 3 & $22-24$ & $3-15$ & $>12$ \\
Pain & 3 & $15,16,20$ & $2-15$ & $>12$ \\
Enjoyment & 6 & $6,14,18,19,21,25$ & $6-30$ & $>23$ \\
Partner & 2 & 28,29 & $2-10$ & $>8$ \\
\hline
\end{tabular}

$\mathrm{S}=$ Sensation; $\mathrm{L}=$ lubrication. Scores indicating a high likelihood of normal function have been derived using discriminant analyses from the current database and should be used as guidelines only. There is a band of scores below these where functional status (excluding partner domain) would be considered as borderline depending on other clinical indices. See table for SFQ score ranges indicative of the likelihood of female sexual dysfunction. 
SFQ score ranges indicative of the likelihood of female sexual dysfunction

\begin{tabular}{llll}
\hline Domain & \multicolumn{3}{l}{ Score range indicating } \\
\cline { 2 - 4 } & $\begin{array}{l}\text { high probability } \\
\text { of female sexual } \\
\text { dysfunction }\end{array}$ & $\begin{array}{l}\text { borderline } \\
\text { sexual function }\end{array}$ & $\begin{array}{l}\text { high probability } \\
\text { of normal } \\
\text { sexual function }\end{array}$ \\
\hline Desire & $5-17$ & $18-22$ & $23-31$ \\
Arousal (S) & $4-10$ & $11-13$ & $14-20$ \\
Arousal (L) & $2-5$ & $6-7$ & $8-10$ \\
Orgasm & $3-8$ & $9-11$ & $12-15$ \\
Pain & $2-8$ & $9-11$ & $12-15$ \\
Enjoyment & $6-16$ & $17-22$ & $23-30$ \\
\hline
\end{tabular}

$\mathrm{S}=$ Sensation; $\mathrm{L}$ = lubrication

When used in conjunction with a clinical sexual history interview, the SFQ scores should be supportive of information derived from the subject (i.e. if the subject proposes that orgasm is her greatest sexual complaint, a score within the range of 3-11 would be expected. A score $>12$ should prompt a review and further discussion).

Where discrepancies between the SFQ score and the sexual problem(s) derived from the sexual history interview arise, the opportunity should be taken to discuss this further with the subject and determine the cause(s) for any discrepancy.

The actual SFQ completed by the subject is as follows:

These questions ask about your sexual activity over the last 4 weeks. Please answer every question by marking one box with a cross. If you are unsure about how to answer, please give the best answer you can. In answering these questions the following definitions apply: Sexual activity includes any activity which may result in sexual stimulation or sexual pleasure, e.g., intercourse, caressing, foreplay, masturbation (i.e. self-masturbation or your partner masturbating you) and oral sex (i.e. your partner giving you oral sex). Sexual life includes both the physical sexual activities and the emotional sexual relationship that you have with your partner.

1. Over the last 4 weeks, how often have you had pleasurable thoughts and feelings about sexual activity? Answer selection: Not at all; Rarely; Sometimes; Often; Very often.

2. Over the last 4 weeks, how often have you wanted to be sensually touched and caressed by your partner? Answer selection: Not at all; Rarely; Sometimes; Often; Very often.

3. Over the last 4 weeks, how often have you wanted to take part in sexual activity? Answer selection: Not at all; Rarely; Sometimes; Often; Very often.

4. Over the last 4 weeks, how often have you initiated sexual activity with your partner? Answer selection: Not at all; Rarely; Sometimes; Often; Very often.

5. Over the last 4 weeks, how often have you been sensually touched and caressed by your partner? Answer selection: Not at all; Rarely; Sometimes; Often; Very often.

6. Over the last 4 weeks, in general, how enjoyable has it been to be sensually touched and caressed by your partner? Answer selection: I have not been touched or caressed; Not enjoyable; Slightly enjoyable; Moderately enjoyable; Very enjoyable; Extremely enjoyable.

7. Over the last 4 weeks, how often did you have a feeling of 'warmth' in your vagina/genital area when you took part in sexual activity? Answer selection: I did not take part in sexual activity; Not at all; Sometimes; Often; Very often; Every time.

8. Over the last 4 weeks, in general, how much 'warmth' did you feel in your vagina/genital area when you took part in sexual activity? Answer selection: I did not take part in sexual activity; None; Slightly 'warm'; Moderately 'warm'; Very 'warm'; Extremely 'warm'.

9. Over the last 4 weeks, how often did you have a sensation of 'pulsating' ('tingling') in your vagina/genital area when you took part in sexual activity? Answer selection: I did not take part in sexual activity; Not at all; Sometimes; Often; Very often; Every time.

10. Over the last 4 weeks, in general, how much 'pulsating' ('tingling') in your vagina/genital area did you notice when you took part in sexual activity? Answer selection: I did not take part in sexual activity; No sensation; A mild sensation; A moderate sensation; A strong sensation; A very strong sensation.

11. Over the last 4 weeks, how often did you notice vaginal wetness/lubrication when you took part in sexual activity? Answer selection: I did not take part in sexual activity; Not at all; Sometimes; Often; Very often; Every time.

12. Over the last 4 weeks, in general, how much vaginal wetness/lubrication did you notice when you took part in sexual activity? Answer selection: I did not take part in sexual activity; No wetness/lubrication; Slightly wet/lubricated; Moderately wet/lubricated; Very wet/lubricated; Extremely wet/lubricated.

13. Over the last 4 weeks, how often did you take part in sexual activity with penetration (e.g., vaginal penetration and intercourse)? Answer selection: I did not take part in sexual activity; Once/twice; 3-4 times; 5-8 times; 9-12 times; $13-16$ times; $>16$ times.

14. Over the last 4 weeks, in general, how much did you enjoy penetration and intercourse? Answer selection: I did not take part in sexual activity; Not enjoyable; Slightly enjoyable; Moderately enjoyable; Very enjoyable; Extremely enjoyable.

15. Over the last 4 weeks, how often did you experience pain in your vagina/ genital area during or after sexual activity (e.g., penetration, intercourse)? Answer selection: I did not take part in sexual activity; Not at all; Sometimes; Often; Very often; Every time.

16. Over the last 4 weeks, in general, how much pain did you experience in your vagina/genital area during or after sexual activity (e.g., penetration, intercourse)? Answer selection: I did not take part in sexual activity; No pain; Slightly painful; Moderately painful; Very painful; Extremely painful.

17. Over the last 4 weeks, how often did you take part in sexual activity without penetration (e.g., masturbation and oral sex)? Answer selection: I did not take part in sexual activity; Once/twice; 3-4 times; 5-8 times; 9-12 times; $13-16$ times; $>16$ times.

18. Over the last 4 weeks, in general, how much did you enjoy sexual activity without penetration (e.g., masturbation, oral sex)? Answer selection: I did not take part in sexual activity; No enjoyment; Slightly enjoyable; Moderately enjoyable; Very enjoyable; Extremely enjoyable.

19. Over the last 4 weeks, how often did you feel emotionally close to your partner when you took part in sexual activity? Answer selection: I did not take part in sexual activity; Not at all; Sometimes; Often; Very often; Every time.

20. Over the last 4 weeks, how often have you been worried or anxious about pain during sexual activity? Answer selection: I did not take part in sexual activity because of being worried or anxious about pain; Not at all; Sometimes; Often; Very often; Every time.

21. Over the last 4 weeks, did you feel good about yourself when you were sexually active? Answer selection: I did not take part in sexual activity; Not at all; Slightly; Moderately; Very; Extremely.

22. Over the last 4 weeks, how often did you have an orgasm when you took part in sexual activity (may be with or without a partner)? Answer selection: I did not take part in sexual activity; Not at all; Sometimes; Often Very often; Every time.

23. Over the last 4 weeks, in general, how pleasurable were the orgasms that you had? Answer selection: I did not have any orgasms; Not pleasurable; Slightly pleasurable; Moderately pleasurable; Very pleasurable; Extremely pleasurable.

24. Over the last 4 weeks, in general, how easy was it for you to reach orgasm? Answer selection: I did not have any orgasms; Very difficult; Quite difficult; Neither easy nor difficult; Quite easy; Very easy.

25. Over the last 4 weeks, how confident have you felt about yourself as a sexual partner? Answer selection: Not at all; Slightly; Moderately; Very; Extremely. 
26. Thinking about your sexual life over the last 4 weeks, how often did you look forward to sexual activity? Answer selection: Not at all; Rarely; Sometimes; Often; Very often.

27. Thinking about your sexual life over the last 4 weeks, did you feel disappointed with your sexual response (e.g., ability to become aroused, lubrication)? Answer selection: I did not take part in sexual activity; Not at all; Slightly; Moderately; Very; Extremely.

28. Thinking about the last 4 weeks, how much did you worry that your partner may look for another sexual relationship because of problems with your sexual life? Answer selection: Not at all; Slightly; Moderately; Very, Extremely.
29. Thinking about the last 4 weeks, how much did you worry about your partner's negative feelings about your sexual life (e.g., partner feeling angry, hurt, rejected)? Answer selection: Not at all; Slightly; Moderately; Very; Extremely.

30. Thinking about your sexual life over the last 4 weeks, how did you feel about the frequency of your sexual activity? Answer selection: A lot less than you desired; A little less than you desired; About right for you; A little more than you desired; A lot more than you desired.

31. In general, how important is being able to have an enjoyable sexual life to you? Answer selection: Not at all; Slightly; Moderately; Very; Extremely.

\section{References}

1 World Health Organization: Defining sexual health: report of a technical consultation on sexual health. Geneva, WHO, 2002.

$\checkmark 2$ Ellenberg M: Impotence in diabetes: the neurologic factor. Ann Intern Med 1971;75:213219.

-3 Rubin A, Babbott D: Impotence and diabetes mellitus. J Am Med Assoc 1958;168:498500.

4 Klein R, Klein BE, Lee KE, Moss SE, Cruickshanks KJ: Prevalence of self-reported erectile dysfunction in people with long-term IDDM. Diabetes Care 1996;19:135-141.

5 Rosen RC, Taylor JF, Leiblum SR, Bachmann GA: Prevalence of sexual dysfunction in women: results of a survey study of 329 women in an outpatient gynecological clinic. J Sex Marital Ther 1993;19:171-188.

6 Laumann EO, Paik A, Rosen RC: Sexual dysfunction in the United States: prevalence and predictors. JAMA 1999;281:537-544.
7 Goldmeier D, Judd A, Schroeder K: Prevalence of sexual dysfunction in new heterosexual attenders at a central London genitourinary medicine clinic in 1998. Sex Transm Infect 2000;76:208-209.

8 Bhasin S, Enzlin P, Coviello A, Basson R: Sexual dysfunction in men and women with endocrine disorders. Lancet 2007;369:597611.

-9 Shifren JL, Davis SR, Moreau M, et al: Testosterone patch for the treatment of hypoactive sexual desire disorder in naturally menopausal women: results from the INTIMATE NM1 study. Menopause 2006;13: 770-779.

10 Bump RC, Mattiasson A, Bo K, Brubaker LP, DeLancey JO, Klarskov P, Shull BL, Smith AR: The standardization of terminology of female pelvic organ prolapse and pelvic floor dysfunction. Am J Obstet Gynecol 1996;175: $10-17$.

11 Salonia A, Munarriz RM, Naspro R, et al: Women's sexual dysfunction: a pathophysiological review. BJU Int 2004;93:1156-1164.
12 Giraldi A, Kristensen E: Sexual dysfunction in women with diabetes mellitus. J Sex Res 2010;47:199-211.

13 Education and treatment in human sexuality: the training of health professionals. Report of a WHO meeting. World Health Organ Tech Rep Ser 1975;572:5-33.

14 Meeking DR, Fosbury JA, Cummings $\mathrm{MH}$, et al: Sexual dysfunction and sexual health concerns in women with diabetes. Sex Dysfunct 1999;I:83-87.

15 Fatemi SS, Taghavi SM: Evaluation of sexual function in women with type 2 diabetes mellitus. Diab Vasc Dis Res 2009;6:38-39.

-16 Schreiner-Engel P, Schiavi RC, Vietorisz D, De Simone Eichel J, Smith H: Diabetes and female sexuality: a comparative study of women in relationships. J Sex Marital Ther 1985;11:165-175.

-17 Safarinejad MR: Female sexual dysfunction in a population-based study in Iran: prevalence and associated risk factors. Int J Impot Res 2006;18:382-395. 